Document downloaded from:

http://hdl.handle.net/10251/127476

This paper must be cited as:

Morant, M.; Pérez, J.; Llorente, R.; Martí Sendra, J. (2009). Combined Analysis of OFDMUWB Transmission in Hybrid Wireless-Optical Access Networks. IEEE Photonics Technology Letters. 21(19):1378-1380. https://doi.org/10.1109/LPT.2009.2026182

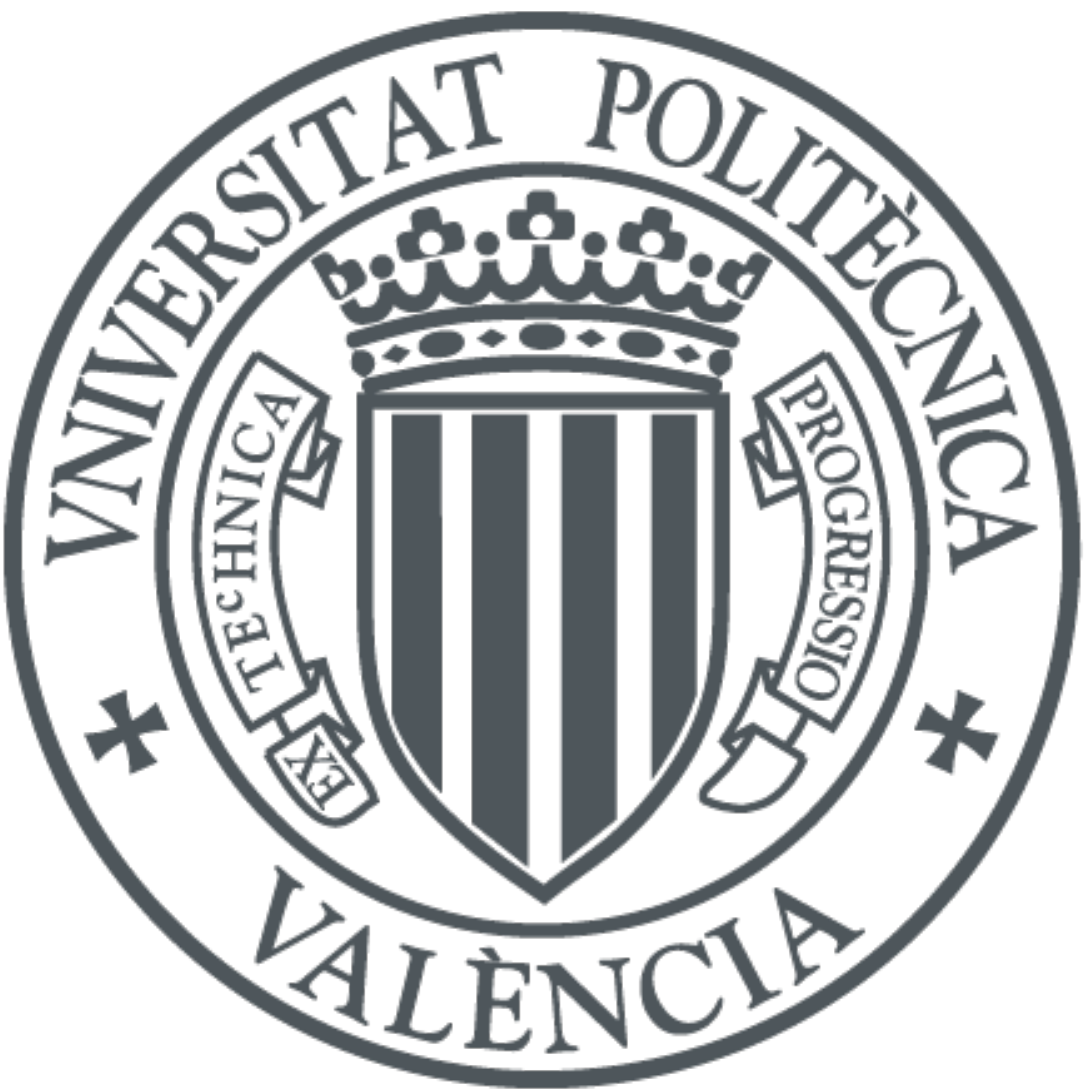

The final publication is available at

http://doi.org/10.1109/LPT.2009.2026182

Copyright Institute of Electrical and Electronics Engineers

Additional Information 


\title{
Combined Analysis of OFDM-UWB Transmission in Hybrid Wireless-Optical Access Networks
}

\author{
Maria Morant, Student Member, IEEE, Joaquin Perez, Student Member, IEEE, \\ Roberto Llorente, Member, IEEE, and Javier Marti, Member, IEEE
}

\begin{abstract}
The hybrid wireless-optical transmission of ultrawideband signals employing orthogonal frequency division multiplexing modulation (OFDM-UWB) as defined in the ECMA-368 standard is experimentally analyzed in this paper. The OFDM-UWB signals provide $400 \mathrm{Mbit} / \mathrm{s}$ per user at optical distances from 5 to $50 \mathrm{~km}$ on standard single-mode fiber (SSMF). The analysis includes the wireless radiation from 0 to $3 \mathrm{~m}$ after optical transmission. The results indicate a maximum errorvector-magnitude (EVM) degradation of $2.5 \mathrm{~dB}$ measured at $1.5 \mathrm{~m}$ radio after $50 \mathrm{~km}$ SSMF optical transmission for the first two UWB channels. This degradation translates to $1 \mathrm{~m}$ maximum wireless reach penalty.
\end{abstract}

Index Terms - Optical communications, optical access networks, fiber-to-the-home networks, ultra-wide band radio

\section{INTRODUCTION}

$\mathrm{U}$ LTRA-WIDEBAND (UWB) wireless is a radio technology targeting high-bitrate short-range indoor data communications. UWB is defined as a radio signal with $20 \%$ fractional bandwidth or, at least, $500 \mathrm{MHz}$ [1]. UWB communication is an unlicensed wireless service allocated in the 3.1 to $10.6 \mathrm{GHz}$ band in current regulation [1-3]. UWB can exceed $1 \mathrm{Gbit} / \mathrm{s}$ bitrate at $1.1 \mathrm{~m}$ radio distances [4]. Two major UWB implementations are available nowadays: Impulse-radio (IR-UWB), and orthogonal frequency-division multiplexing modulation -based (OFDM-UWB) [2].

Hybrid wireless-optical access based on the transmission of OFDM-UWB signals in fiber-to-the-home (FTTH) networks is a natural step forward in the evolution of the access network. This approach employs the FTTH optical links to optically distribute the UWB signal in its native format from a central location to the remote customer premises for its further wireless transmission [5]. This access technique exhibits several advantages: (i) Optical distribution of OFDM-UWB signals in the band from 3.1 to $10.6 \mathrm{GHz}$ enables the provision of a large number of UWB channels employing only one light. (ii) OFDM-UWB is cost-efficient. The signal transmitted to

Manuscript received December 12, 2008. This work has been partly funded by the FP7-ICT-216785 UCELLS project. Maria Morant's work is supported by Spain FPU MICINN grant AP2007-01413. BONE ("Building the Future Optical Network in Europe") NoE is acknowledged.

Maria Morant, Joaquin Perez, Roberto Llorente and Javier Marti are with the Wireless-Photonics Integration group in Nanophotonics Technology Centre, Universidad Politécnica de Valencia, 46022 Valencia, Spain (e-mail: \{mmorant, joapeso, rllorent, jmarti\}@ntc.upv.es). user premises is received by commercially available low-cost UWB devices. (iii) Optical reception and radio transmission is flexible. As re-modulation and/or frequency up-conversion are not needed, the costumer-side receiver is agnostic regarding the frequency band and the specific modulation employed.

The optical distribution of IR-UWB and OFDM-UWB signals in FTTH networks was first proposed in [5]. Mathematical modeling was performed for both UWB signals in [6]. The results indicated that OFDM-UWB signals are better suited for optical transmission as IR-UWB signals are more sensitive to nonlinear distortion [7]. The work herein presented pushes forward this concept analyzing, for the first time to our knowledge, the combined performance of dualchannel OFDM-UWB optical and further radio transmission.

\section{OFDM-UWB HYBRID WIRELESS-OPTICAL ACCESS}

The proposed hybrid wireless-optical access based on OFDM-UWB signals is depicted in Fig. 1. This figure shows an optical line terminal (OLT) -located at the operator core network, typically in the central office (CO)- that distributes the signal through a SSMF-based FTTH network to an optical network units (ONU) located at the customer premises. Depending on the transmission distance, optical amplifier sections are required in the FTTH links [8]. OFDM-UWB is especially well suited in this case as optical transmission impairments like chromatic dispersion, intrachannel nonlinear distortion and nonlinear phase noise can be compensated by electronic processing at the receiver side [9].

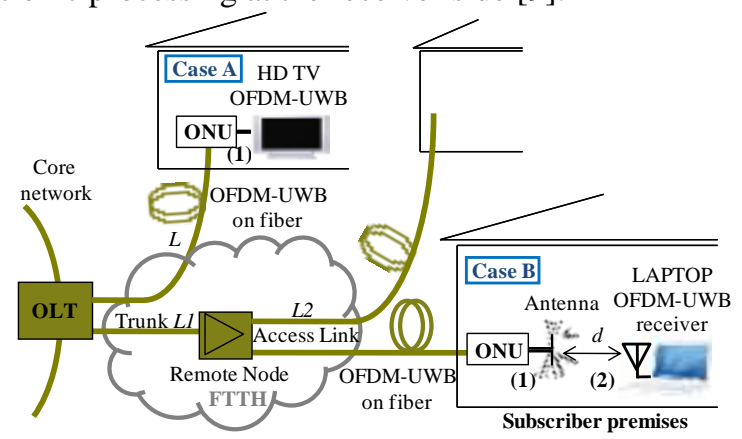

Fig. 1. Proposed concept for UWB wireless-integration in FTTH networks. At subscriber premises the UWB signals are extracted and in Case A feed into an enabled receiver, and in Case $\mathrm{B}$ radiated to a user device.

Two typical FTTH optical path architectures are considered: $1^{\text {st }}$ Trunk fiber links without optical amplification with maximum reach of $25 \mathrm{~km}$, and $2^{\text {nd }}$ ) Fiber links with inline optical amplification with maximum reach of $50 \mathrm{~km} \mathrm{[10].}$ 
These distances exceed typical FTTH range $(\sim 10 \mathrm{~km})$ and permit to investigate the operational limits [10]. As shown in Fig. 1, after FTTH optical transmission, the OFDM-UWB signals can be photodetected at the ONU and demodulated (Case A in Fig. 1) or, they can be photodetected, amplified, and radiated for its wireless transmission (Case B in Fig. 1).

\section{EXPERIMENTAL ANALYSIS}

The transmission performance for Cases A and B in Fig. 1 are analyzed by the setup shown in Fig. 2. This setup comprises two OFDM-UWB channels (named Ch 1 and $\mathrm{Ch}$ 2) generated with two Wisair DV9110 modules following ECMA-368 standard [2]. The bitrate of each OFDM-UWB channel is $200 \mathrm{Mbit} / \mathrm{s}$ giving an aggregated bitrate of $400 \mathrm{Mbit} / \mathrm{s}$ per user. The two OFDM-UWB channels are amplified and externally modulated by a Mach-Zehnder electro-optical modulator (MZ-EOM) and transmitted through SSMF-based optical paths of $L=5,10$ and $25 \mathrm{~km}$ without inline optical amplification, and $L 1=L 2=25 \mathrm{~km}$ (total reach of $50 \mathrm{~km}$ ) with inline optical amplification. The launched optical power is controlled by an erbium-doped fiber amplifier -EDFA(CO) in Fig. 2- typically located at the OLT [8]. The optical paths with $50 \mathrm{~km}$ reach also includes inline (IL) optical amplification -EDFA(IL) in Fig.2-. After optical transmission, the OFDM-UWB signal is photodetected (PIN), amplified and its error-vector-magnitude measured (Agilent DSA 80000B). The OFDM-UWB equivalent isotropic radiated power (EIRP) is adjusted at the ONU to $-41.3 \mathrm{dBm} / \mathrm{MHz}$, the maximum level allowed in current regulation [1]. Further wireless transmission is done by two omnidirectional patch antennas (In4Tel-omni, $0 \mathrm{dBi}$ ). After wireless transmission the OFDMUWB signal is amplified and the EVM is measured again. Table I summarizes the main OFDM-UWB signal parameters and the device specification in the experimental work.

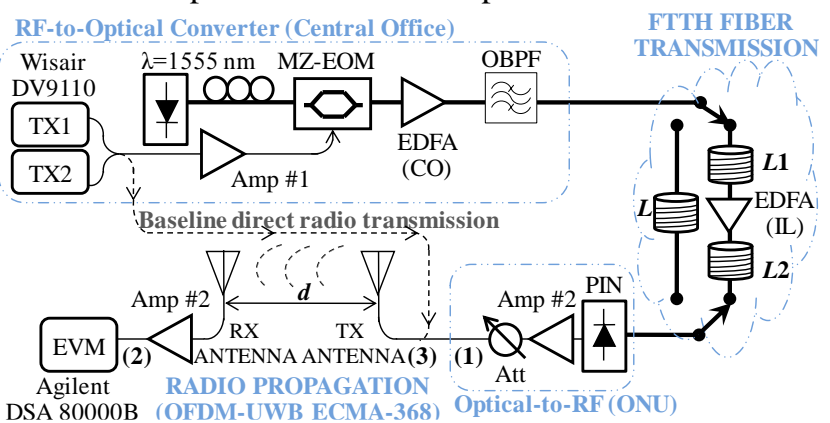

DSA 80000B (OFDM-UWB ECMA-368) Optical-to-RF (ONU)

Fig. 2. Experimental setup for OFDM-UWB combined performance evaluation of optical and wireless transmission in hybrid access networks.

TABLE I. OFDM-UWB PARAMETERS AND DEVICE SPECIFICATIONS

\begin{tabular}{|c|c|c|c|c|}
\cline { 2 - 5 } \multicolumn{1}{c|}{} & Channel 1 & Channel 2 & \multicolumn{2}{c|}{ Device } \\
\hline Center freq & $3.432 \mathrm{GHz}$ & $3.96 \mathrm{GHz}$ & Amp\#1 & $\mathrm{G}=21 \mathrm{~dB}$ \\
\hline Bandwidth & \multicolumn{2}{|c|}{$528 \mathrm{MHz}[2]$} & Amp\#2 & $\mathrm{G}=26 \mathrm{~dB}$ \\
\hline Modulation & $\begin{array}{l}\text { QPSK OFDM 128 carriers } \\
\text { (6 null and 12 pilot tones) }\end{array}$ & $\begin{array}{c}\text { EDFA(CO) } \\
\text { EDFA(IL) }\end{array}$ & $\begin{array}{c}\mathrm{G}=23 \mathrm{~dB} \\
\mathrm{P}_{\mathrm{sat}}=13 \mathrm{dBm}\end{array}$ \\
\hline Bitrate & \multicolumn{2}{|c|}{$200 \mathrm{Mbit} / \mathrm{s}$} & Att & $0-9 \mathrm{~dB}$ \\
\hline EIRP & \multicolumn{2}{|c|}{$-41.3 \mathrm{dBm} / \mathrm{MHz}[1]$} & Antennas & $\mathrm{G}=0 \mathrm{dBi}$ \\
\hline
\end{tabular}

Two sets of measurements have been done to analyze Cases A and B in Fig. 1: First, the EVM is measured after optical distribution -before TX antenna, point (1) in Fig. 2-. Second, the EVM is measured after radio transmission -after RX antenna, point (2)-. The measurements consider radio distances $(d)$ from 0 to $3 \mathrm{~m}$ for all optical transmission ranges.

\section{OPTICAL TRANSMISSION PERFORMANCE}

The Case A in Fig. 1 is analyzed measuring the EVM of the received OFDM-UWB signal after optical transmission. The impact of the optical noise introduced by the $\operatorname{EDFA}(\mathrm{CO})$ is analyzed varying the amplification level. Fig. 3 shows the resulting EVM measured at point (1) in Fig.2 for both OFDMUWB channels before radiation. Measurements have been done for four FTTH optical links (5, 10, 25 and $50 \mathrm{~km}$ reach) and in back-to-back (B2B) configuration (i.e. $L=0 \mathrm{~km}$ ) to evaluate the effect of fiber length in the system performance.

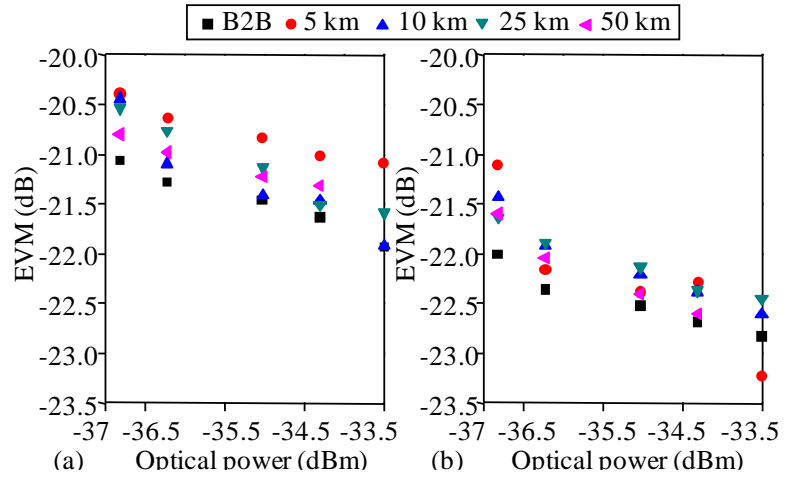

Fig. 3.EVM vs. fiber vs. optical power before photodetection (a) Ch 1,(b)Ch 2

In Fig. 3 it can be observed that the EVM variation at a given optical transmission distance range from $-20.75 \mathrm{~dB}$ to $-22 \mathrm{~dB}$ for channel 1 (Ch 1), and range from $-21 \mathrm{~dB}$ to $-23 \mathrm{~dB}$ for channel 2 (Ch 2). Adequate EVM values (below the -14.5 dB ECMA-368 threshold) are obtained for all optical ranges measured. The results indicate that the EDFA amplification is not a limiting factor in the proposed approach for the SSMF ranges considered.

\section{COMBINED OPTICAL/RADIO TRANSMISSION PERFORMANCE}

The Case B depicted in Fig. 1 is analyzed now. The EVM is measured after wireless radiation of the OFDM-UWB signal with- and without optical transmission. The baseline performance is obtained when the signal is just radiated connected directly to point (3) as shown in Fig. 2 (without using optical conversion). The EVM measured at point (2) in Fig. 2 in this case is shown in Table II for different radio distances. Ch 2 performance is worse than $\mathrm{Ch} 1$, due to the frequency response of the electrical amplifiers and antennas.

TABLE II. BASELINE EVM MEASURED WITHOUT OPTICAL TRANSMISSION

\begin{tabular}{|c|c|c|c|c|}
\cline { 2 - 5 } \multicolumn{1}{c|}{} & $\boldsymbol{d}=\mathbf{0 . 5} \mathbf{~ m}$ & $\boldsymbol{d}=\mathbf{1 ~ \mathbf { ~ }}$ & $\boldsymbol{d}=\mathbf{1 . 5} \mathbf{~ m}$ & $\boldsymbol{d}=\mathbf{2} \mathbf{~ m}$ \\
\hline EVM Channel 1 & $-20.39 \mathrm{~dB}$ & $-17.81 \mathrm{~dB}$ & $-14.6 \mathrm{~dB}$ & $-13.18 \mathrm{~dB}$ \\
\hline EVM Channel 2 & $-18.63 \mathrm{~dB}$ & $-15.79 \mathrm{~dB}$ & $-12.72 \mathrm{~dB}$ & $-10.37 \mathrm{~dB}$ \\
\hline
\end{tabular}

It is important to note that the wireless radiated power is adjusted again in all the cases to the EIRP regulation limit of $-41.3 \mathrm{dBm} / \mathrm{MHz}$ (shown in Fig. 4 as a dashed line). This is done adjusting the electrical amplification by the variable attenuator shown in Fig. 2. Fig. 4(a) shows the power spectrum density (PSD) of the two OFDM-UWB channels under study after $25 \mathrm{~km}$ SSMF as an example. The corresponding spectrum ( $25 \mathrm{~km}$ optical transmission, $d=1.5 \mathrm{~m}$ ) is shown in Fig. 4(b) for comparison. The constellations measured for each OFDM-UWB channel are shown in Fig. 4(c)-(f). Ch 2 exhibits slightly higher distortion due to the frequency response of electrical and optical components. 


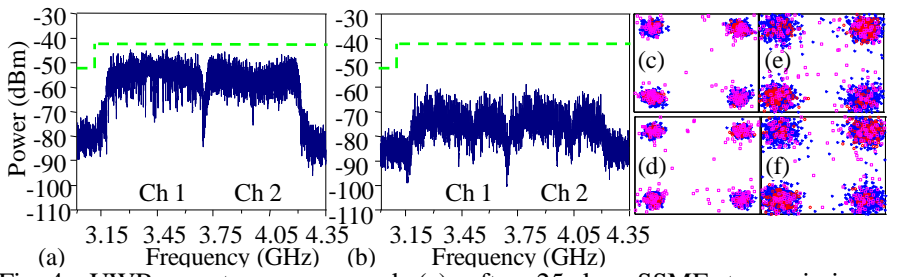

Fig. 4. UWB spectrum measured (a) after $25 \mathrm{~km}$ SSMF transmission, photodetection and amplification -point (1) in Fig. 2-; and (b) after $d=1.5 \mathrm{~m}$ radio propagation -point (2) in Fig. $2-$. $\mathrm{RBW}=1 \mathrm{MHz}$. And received constellations for: (c) Ch 1, (d) Ch 2 after 25 km SSMF -point (1) in Fig. 2-; (e) Ch 1,(f) Ch 2 after $d=1.5 \mathrm{~m}$ radio propagation -point (2) in Fig. 2-.

Fig. 5 shows the EVM measured at point (2) in Fig. 2 after radio transmission from 0 to 3 meters for all optical distances considered, for a fixed optical power before photodetection of $-34.3 \mathrm{dBm}$. Further study on the results demonstrated that this performance can be extended for the other optical powers employed taking into account the difference depicted in Fig. 3. The EVM threshold is marked as a dashed line. In this case, the EVM remains almost constant for all the optical transmission distances. Therefore the optical path is not a limiting factor of the proposed approach in this case.
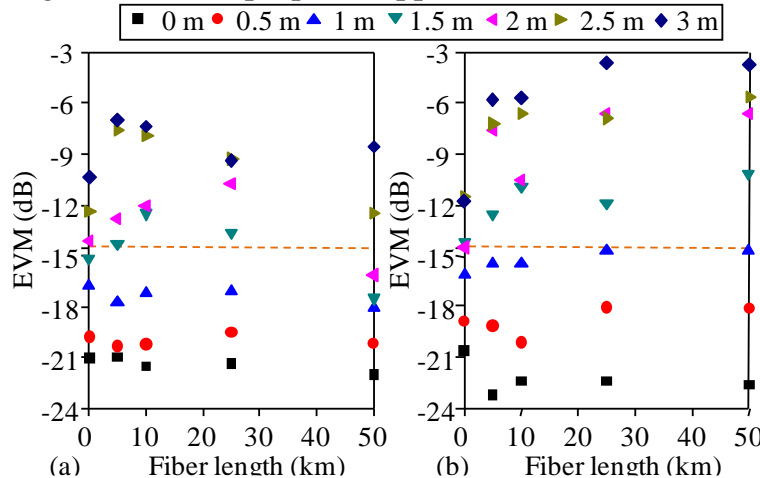

Fig. 5. EVM vs. wireless distance vs. fiber length transmission with optical power before photodetection of $-34.3 \mathrm{dBm}$ for (a) Ch 1 and (b) Ch 2 .

Fig. 6 shows the EVM measured for the same wireless radio distances. The EVM threshold is reflected in a wireless range for Ch 1 of $2 \mathrm{~m}$ (after $5 \mathrm{~km}$ of SSMF), $1.5 \mathrm{~m}$ (after $10 \mathrm{~km}$ SSMF), and $1 \mathrm{~m}$ in any other optical path configuration. For Ch 2 only B2B configuration reaches $1.5 \mathrm{~m}$ wireless distance and $1 \mathrm{~m}$ radio is achieved in any optical path configuration. Fiber propagation degrades the UWB signal to noise ratio (SNR) imposing a maximum wireless reach penalty of $1 \mathrm{~m}$ (from $2 \mathrm{~m}$ in B2B configuration to $1 \mathrm{~m}$ for $50 \mathrm{~km} \mathrm{SSMF}$ ).
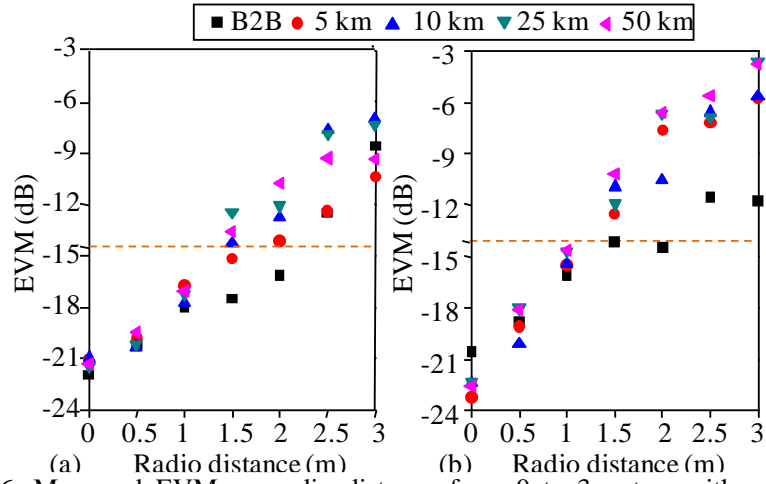

Fig. 6. Measured EVM vs. radio distance from 0 to 3 meters with optical power of $-34.3 \mathrm{dBm}$ for different FTTH configurations (a) Ch 1 and (b) Ch 2.

Comparing the results in Fig. 6 with the baseline wireless transmission performance reported in Table II, it can be observed that the worst-case EVM degradation introduced by optical transmission is $2.13 \mathrm{~dB}$ for $\mathrm{Ch} 1$ (radio distance $1.5 \mathrm{~m}$, $25 \mathrm{~km}$ SSMF) and $2.5 \mathrm{~dB}$ for $\mathrm{Ch} 2(1.5 \mathrm{~m}$ radio distance, $50 \mathrm{~km}$ SSMF). This EVM penalty comes from the optical noise, as in the extreme case of $50 \mathrm{~km}$ optical transmission, the optical amplification required is very high (about $18 \mathrm{~dB}$ ). The experimental results also indicate that in the case of an optical access range of $10 \mathrm{~km}$, the radio penalty measured is $0.07 \mathrm{~dB}$ EVM for Ch 1 and $0.37 \mathrm{~dB}$ EVM for Ch 2, which corresponds to less than $50 \mathrm{~cm}$ radio transmission penalty.

\section{CONCLUSIONS}

It has been demonstrated the successful distribution of standard compliant (ECMA-368) dual-channel OFDM-UWB providing $400 \mathrm{Mbit} / \mathrm{s}$ bitrate per user with $0.38 \mathrm{Bit} / \mathrm{s} / \mathrm{Hz}$ spectral efficiency over 5, 10, 25 and $50 \mathrm{~km}$ SSMF-based FTTH paths without dispersion compensation. Two application cases are considered: In Case A the OFDM-UWB signal is distributed in optical domain. The OFDM-UWB signal is photodetected, amplified and analyzed. The measurements results indicate that optical transmission is not a limiting factor as the OFDM-UWB EVM threshold is always achieved. In Case B, the OFDM-UWB signal is optically transmitted and wirelessly radiated at distances up to $3 \mathrm{~m}$. The experimental results indicate that $1.5 \mathrm{~m}$ wireless range is achieved after $10 \mathrm{~km}$ SSMF transmission. $1 \mathrm{~m}$ wireless range is achieved after $50 \mathrm{~km} \mathrm{SSMF}$. Optical transmission degrades OFDM-UWB SNR giving a maximum wireless reach penalty of $1 \mathrm{~m}$ (over B2B) measured after $50 \mathrm{~km} \mathrm{SSMF} \mathrm{transmission.}$ Comparing the OFDM-UWB performance with- and without optical transmission it can be observed a maximum signal degradation of $2.13 \mathrm{~dB}$ for $\mathrm{Ch} 1$ and $2.5 \mathrm{~dB}$ for $\mathrm{Ch} 2(1.5 \mathrm{~m}$ radio distance). This degradation is mainly due to the optical amplification (EDFA). Other factors as chromatic dispersion, reflected in the carrier suppression effect, gives $0.18 \mathrm{~dB}$ power attenuation after photodetection [11], not being a limiting factor for the optical transmission distances considered.

\section{REFERENCES}

[1] FCC 02-48, "Revision of Part 15 of the Commission's Rules Regarding Ultra-Wideband Transmission Systems", First Report, April 2002.

[2] ECMA-368: "High rate ultra wideband PHY and MAC Standard", 2007.

[3] ECC Report 64, "The protection requirements of radio communications systems below $10.6 \mathrm{GHz}$ from Generic UWB applications", Feb 2005.

[4] T. Lunttila, et al. "Advanced Coding Schemes for a Multi-Band OFDM Ultrawideband System towards 1 Gbps", CCNC, pp.553-557, 2006.

[5] R. Llorente, et al. "Ultra-Wideband Radio Signals Distribution in FTTH Networks", IEEE Phot. Techn. Lett, vol. 20, 11, pp.945-947, June 2008.

[6] M. Jazayerifar, B. Cabon, and J. A. Salehi, "Transmission of Multi-Band OFDM and Impulse Radio Ultra-Wideband Signals Over Single Mode Fiber", IEEE JLT, vol. 26, 15, pp.2594-2603, Aug. 2008.

[7] A. Kaszubowska-Anandarajah, P. Perry and L.P. Barry,"Hybrid radio over fiber system for generation and distribution of UWB signals",ICTON,p.82-85,June 2008.

[8] J. Prat, "High-Density Passive Fiber-to-the-Home Networks", Proc. 7th Intl Conference Transparent Optical Networks, vol. 2, pp.33-37, 2005.

[9] A.J. Lowery, L. B. Du, J. Armstrong,."Performance of Optical OFDM in Ultralong-Haul WDM Lightwave Systems" IEEE JLT, vol. 25, 1,pp.131-138, Jan. 2007.

[10] K. A. Janjua, S.A. Khan, "A comparative economic analysis of different FTTH Architectures”, WICOM2007, pp. 4979-4982, Sept. 2007.

[11] H. Schmuck, "Comparison of optically millimeter-wave system concepts with regard to chromatic dispersion", Electronics Letters, vol. 31, pp. $1848-1849,1995$. 